\title{
From Access to Gratification: Towards an Inclusive Digital Society
}

\author{
Dr. Ali Salman (Corresponding author) \\ School of Media and Communication Studies \\ Universiti Kebangsaan Malaysia (The National University of Malaysia) \\ 43600 Bangi, Selangor, Malaysia
}

Tel: 60-19-612-6568Ｅ-mail: asalmanphd@gmail.com

Prof. Dr. Samsudin A. Rahim

School of Media and Communication Studies, The National University of Malaysia

43600 Bangi, Selangor, Malaysia

Tel: 60-19-310-4542Ｅ-mail: samsudinrahim@yahoo.com

Received: February 20, 2012

Accepted: March 13, 2012 Published: April 16, 2012

doi:10.5539/ass.v8n5p5

URL: http://dx.doi.org/10.5539/ass.v8n5p5

This project is funded by the Universiti Kebangsaan Malaysia under the research code: UKM-SK-05-FRGS0078-2009

\begin{abstract}
The aim of this paper is to trace the use of Internet between natives and migrants and examine how the difference in age affects the gratifications derive from the usage leading to digital inclusion. The issue of broadband access to achieve digital inclusion has gained momentum over the years. In Malaysia, access which is the first level of exposure to Information Communication Technology (ICT) has been largely achieved. Recent research has attempted to expand the conception of the divide to move beyond access to consider issues of proficiency and gratification. This study uses a survey research to obtain data. Some 600 respondents, who are divided into natives and migrants were sampled for the study. The literacy/knowledge and skills for internet applications for both the natives and migrants respondents is above average. Information and socialisation gratifications are the main gratifications derived from using the Internet for both the natives and migrants.
\end{abstract}

Keywords: Beyond digital divide, Strategies for digital inclusion, Gratifications, Natives, Migrants, Internet

\section{Introduction}

In the mid 90's countries and government were more concerned with the issue of digital divide, especially rural / urban divide and economic divide (Campbell, 2001). It is now time to look beyond these types of divide. As it is now, in Malaysia, access which is the first level of exposure to ICT has been largely achieved (United Nations, 2005). Thus what is required is the next level concerning how to get gratification from using the various facilities available on the Internet.

It has been roughly over a decade since the term "Digital Divide" was first introduced as an issue that materially affects the social, cultural, and economic well-being of countries. The Digital Divide denotes the gap between information technology haves and have-nots. In those early years of the information age, experts in both the public and private sectors questioned the impact of this divide on society. The issue is what would happen to those left out of digital life - the "have-nots" (Wynne \& Cooper, 2007). From then on, access to information technology has become a socio-economic given. The OECD (2001) defines the digital divide as differences between individuals, households, companies, or regions related to the access to and usage of ICT. The divide may appear due to historical, socioeconomic, geographic, educational, behavioural, or generation factors, or due to the physical incapability of individuals (Cullen, 2001, p. 311). 
It is a fact that those who have online access and are digitally literate are more likely to be economically secured and at less risk than those who do not. The concept of an effective "Digital Inclusion" strategy is one of the most significant challenges facing countries.

Digital inclusion is about access to and use of the Internet. It is a term that encompasses activities related to the achievement of an inclusive information society (Hebatallah El Gamal, 2010). Under such a definition, new developments in technology convert the prospects of a digital divide into opportunities for "digital cohesion," bringing the benefits of the Internet and related technologies to all segments of the population, including people who are disadvantaged due to education, age, gender, disabilities, ethnicity, and remote geographical areas (Kent $\&$ McClure, 2009). Digital inclusion covers mainly the development of appropriate policies, maintenance of a knowledge base, research \& technology development and deployment, and best practices dissemination (ITU, 2010).

A digital inclusion strategy demands that an approach which is holistic and multifaceted including all stakeholders and incorporating elements that will bring about an increase in digital literacy. Access alone, however, does not equal Digital Inclusion. Inclusion should maximise access to the Internet by reducing inequalities due to level of usage and gratification. The public sector and all stake holders must actively pursue broader initiatives to meet the challenges resulting from digital inequalities (Kent \& McClure, 2009).

In the west, studies have been done on digital divide among ethnics, natives and migrants users of new media, whereas in developing countries studies such as these are lacking. Analyses within sub-samples defined by age and socio-economic status reveal that there are notable differences in uses and gratifications across subgroups. Scholars are of the opinion that even as the gap in Internet access is closing, inequalities in Internet use and individuals' gains from these interactions may persist. These inequalities may also be seen in the ability of individuals to use the Internet in ways that allow them to meet basic needs (Cho, Zuniga, Rojas \& Shah, 2003).

Therefore, it is timely to see whether similar patterns emerge in developing countries. More generally, this research reinforces the view that the digital divide should move beyond a simple consideration of access to examine more closely factors such as access and usage, literacy/knowledge and skills and their connections to gratifications gained. Hence, the objective of this paper is to trace the use of internet between natives, age between 18 and 30, and migrants above 31 years of age in relation to gratifications obtained. Based on survey data, this article examines how the difference in age of the natives and migrants affect the gratifications derive from the use of the Internet in relation to access and hours of usage, literacy/knowledge and skill of the users. The study will look at the relationship between the main variables with gratifications. Also, the effects of the main variables (IV) on gratification (DV) will be presented using multiple regressions.

\section{Literature Review}

The Internet and cyberspace may not have fully reached their potential to create the large - scale social change some have argued it would provide. However, rapid expansion has generated new social status and added layers of opportunities to human relationships, communication, information and ultimately, user behaviour. This expansion of the new technologies has raised concerns about equitable access in under-served social sectors in what is known as the digital divide-i.e., the divide between those with access to the Internet and those without access to the opportunities such "connectedness" provides (Schiller 2000).

The issue of broadband access to achieve digital inclusion has gained momentum over the years. Countries have been putting their houses in order to realise this objective. Finland was the first country to declare broadband access a civil right, in October 2009. Spain followed a month later and granted the right to broadband as well. Both countries pledged to have connections of at least $1 \mathrm{Mbps}$ available to all citizens at affordable prices by 2011 (Kunigami, A. M. 2010.).

However, the digital divide is more than an issue of access. It is a sociological phenomenon reflecting broader social, economic, cultural, and learning inequalities. Most of the studies clearly illustrate that a range of factors and contextual characteristic are responsible for differences. No single factor-gender, age, race, education, income or geographic location - can alone shed sufficient light on the issue to fully explain the access gap (Wahl et al. 2000). Yet research has documented the importance of basic factors, individually and in combination, on the digital divide (Hirt, Murray, and McBee 2000; Hoffman and Novak, 1999; Howard et al. 2001; Kavanaugh and Patterson, 2001).

In a similar tone Stiakakis, Kariotellis and Vlachopoulou (2010) claim the digital divide is evolving to digital inequality with the presence of socio-economic disparities inside the 'online population'. They examined two main dimensions of the digital inequality, namely 'skills' and 'autonomy' of Internet users. For the skill 
dimension, the level of formal education was selected, while the density of population in different geographical areas was selected as a representative variable for the autonomy dimension. The research was focused on the member states of the European Union (EU). The findings state that the EU already faces the problem of digital inequality to a comprehensive rate, since there are large disparities among the European countries with regard to the aforesaid variables.

Having access to the Internet may not necessarily mean there will be no more gaps or divide in the subsequent usage of the technology. Scholars of new media have identified several factors which may inhibit the smooth usage of the Internet, in what they term beyond the digital divide. Among the divides identified are the access divide (race, ethnicity, education and income), skills divide (technical competence and information literacy), economic opportunity divide (those with computer knowledge get jobs and rise in the ranks of their organizations) and democratic divide (Mossberger, Tolbert and Stansbury, 2003).

In addition, recent research has attempted to expand the conception of the divide to move beyond access to consider issues of proficiency and satisfaction. Even if gaps have diminished in terms of access significant gaps may remain in terms of patterns of use and gratifications gained (Katz et al. 2001; Smolenski 2000). Many researchers and technologists argue that these gaps remain a persistent problem to this day, especially in terms of age and socio-economic status, with the poor and elderly remaining the most "disconnected" from the virtual world (Norris 2001).

\section{Methodology}

The study employed a survey methodology to obtain data. Some 600 respondents comprising residents of the Klang Valley were sampled for the study. The 600 respondents were divided into natives (300) and migrants (300). The natives were in the age range of 18 to 30 years old, while the migrants were in the age range of 31 and above. The questionnaires for the study were administered with the help of undergraduate and graduate student enumerators. Both descriptive and inferential analyses were used to analyse the data.

\section{Results}

The result of the study is presented in two parts, descriptive and inferential data. The descriptive data comprise of the demographic background of the respondents, means, and percentage of some of the main variables. The inferential data on the other hand consist of reliability, correlation and multiple regression analysis.

\subsection{Demographic background}

As shown in Table 1, the respondents consist of an equal number of male and female for both the natives and migrants. In terms of employment, $76.3 \%$ of the migrants have full time employment as compared to $41.7 \%$ for the natives. Students made up $46.7 \%$ of the natives as against $4.7 \%$ for the migrants. As expected, the migrants' monthly household income exceeds that of the natives, especially the RM1500 and above bracket.

\subsection{Descriptive Statistics}

\subsubsection{Internet Access}

One aspect of measuring internet access in a given population is the number subscribers to the Internet. From Table $2,74 \%$ of the migrants have internet access/subscription at home as against $71.7 \%$ for the natives. The natives have used the Internet longer than the migrants where $18.7 \%$ of the native respondents have used the Internet 4 to 5 years and $38 \%$ for more than 5 years. For the migrants, $11 \%$ and $31.3 \%$ of the respondents have used the Internet for 4 to 5 years and more than 5 years respectively. In the same way, the natives spend more hours using the Internet than the migrants. In terms of hours of Internet usage, $17 \%$ of the natives as against $16 \%$ of the migrants use the Internet 4 to 7 hours per week. Likewise, $15.3 \%$ of natives as against $10 \%$ of migrants use the Internet 8 to 11 hours per week, while $33 \%$ of the natives as compared to $24 \%$ of the migrants use the Internet 12 to 14 hours per week.

Table 3 presents the means and standard deviation for knowledge of internet applications for the respondents. To give the mean some meanings, 5 is the highest mean. Thus the following are the values associated with the means: 1-2 very low; $2-2.49$ low; $2.50-2.99$ average; $3-4$ high; $4-5$ very high. From the table, social media (SM) application by natives has the highest mean, 3.92. The SM mean for the migrants is also quiet high, 3.57 . Knowledge of Search engine is also high for both the natives (3.90) and migrants (3.64). The natives supersede the migrants in most aspects of the Internet applications. One of the lowest means for the migrants is blogging, 2.94, as against 3.19 for the natives. The lowest means for both the natives (2.66) and the migrants (2.72) are e-shopping/e-business applications. 
In terms of gratifications (Table 4) derive from the Internet, the highest means recorded for the natives are for current issues (4.22), information (4.30), easy making friends (4.09), help in solving problems (4.06) and help relieve boredom (4.10). While for the migrants, the highest means are for current issues (4.12), information (4.18), and easy making friends (4.02). Among the lowest means recorded for both the natives and migrants are those for Internet shopping, 3.21 and 3.22 respectively. Gratification from playing online games (3.08) is the lowest mean for the migrants.

\subsection{Inferential statistics}

\subsubsection{Reliability}

Analysis for the inferential statistics includes reliability, correlation, and multiple regression analysis. Table 5 presents the reliability index of the variables for the 600 respondents, both natives and migrants. The reliability index, i.e. the Cronbach Alphas of the variables are very satisfactory except the Technological Motivation variable which is quite low at 0.67 . The highest Cronbach Alpha is 0.93 for participation.

\subsubsection{Multiple Regressions of Gratification and the main variables}

The results for the multiple regression analysis for the natives revealed three models (Table 6). In model A for the natives, the predictor is technology motivation with Adjusted $\mathrm{R}$ square of .315 which is significant at .000 and for model $\mathrm{B}$ technology motivation and literacy knowledge are the predictors and Adjusted $\mathrm{R}$ square increased to .420 with R Square Change of .105 significant at .000. The third model, C, consist of technology motivation, literacy knowledge and skill as contributing to the variations in gratifications and Adjusted R Square increased to .433 with an increase of .013 and significant at .006 . Thus the contribution of the variation in gratification by skill is minimal. The three variables contributed $43.3 \%$ of the variations in gratifications. In terms of $\mathrm{T}$ value, technology motivation $(\mathrm{t}=7.928)$ has the highest, followed by literacy knowledge $(\mathrm{t}=4.213)$ and skill $(\mathrm{t}=2.793)$ has the lowest.

Similarly, for the migrants (Table 6), the multiple regression analysis revealed three models, where in model A, the predictor is literacy knowledge with Adjusted R square of .337, which is significant at .000 and for model B, literacy knowledge and technology motivation are the predictors and adjusted $\mathrm{R}$ square increased to .414 with $\mathrm{R}$ Square Change of .077 significant at .000 .

The third model, C, includes skill and Adjusted R Square increased to .433 with an increase of .019 and significant at .001 . Thus the three predictors contributed $43.3 \%$ of the variations in gratifications. Another way of looking at the regression analysis is the $\mathrm{T}$ values of the predictor variables. The highest $\mathrm{T}$ value for the migrants is literacy knowledge $(\mathrm{t}=6.054)$.

Looking at the beta values (Table 7), the same predictors that have effects on gratifications, which are motivation technology and literacy knowledge, have the highest beta for both the natives (beta $=.388$ ) and migrants (beta $=.304$ ), respectively.

\section{Discussion}

Having internet connection or subscription at home, though not the only yardstick to measuring accessibility to internet, is still vital in narrowing or closing the gap in digital divide. About two-thirds of both the natives and migrants in this study have internet connection or subscription at home. This shows that access to internet is no longer a problem for both the natives and migrants, though a slightly more migrants have internet connection at home than the natives. The reason for this could be the large number of the migrants who might be working as compared to the natives who might be studying, hence could not afford to pay subscription fees.

The native respondents in this study, born in the Internet age, have used the Internet for many years than the migrants. This is expected as some of the migrants might have been reluctant to embrace the Internet at its inception due to their age. For this group of migrants, internet is a technology for the young. Yet still, as the result of this study shows, the percentage of the migrants who use the Internet for more than five years is still encouraging.

Another aspect of looking at internet access and usage is in terms of hours of usage. More natives use the Internet more hours in a week than the migrants. The reason could be that the natives who are young and also some of them are still furthering their education might use the Internet as a source of getting educational materials for their studies. Furthermore, the natives spend hours socialising on the net with friends and family.

The use of SM is the trend now, especially among the young generation. The result of this study also confirms that the knowledge/literacy in using SM is the highest among other internet applications among the natives, who are young. In order to search for information on the Internet the user must have knowledge of the various search 
engines. For the natives knowledge of search engines is the second highest, while for the migrants it is the highest. This is somehow interesting as knowledge of SM and search engines have surpassed knowledge of email. Perhaps some of the native internet users had exposure to SM before email applications, hence having more knowledge on SM application than email. The advent of Facebook which has revolutionized social media has contributed to this. Before the advent and consequent popularity of Facebook, there existed other SM applications like Myspace, Tagged etc. As found in other studies on internet usage among Malaysians (Hasim and Salman, 2010), this study also found out that the least knowledge on internet applications for both the natives and migrants is the knowledge in using e-shopping/e-business applications.

Some of the important aspects which can lead to digital inclusion are the various gratifications derive from using the Internet (Katz et al. 2001; Smolenski 2000). The high gratifications both the natives and the migrants get from using the Internet are the information and socialization gratifications. For the natives, solving problems and relief from boredom are additional high gratifications they derive from using the Internet. Overall, the gratifications both the natives and migrants derive from using the Internet are above average and point to that fact that using the Internet is indeed gratifying.

As mentioned somewhere in the paper, gratifications from using the Internet will in the long run lead to digital inclusion. It is, therefore, important to determine how the other variables of the study contribute to the variations in gratifications. In other words, the effect and impact of these variables on gratifications need to be understood. From the results of the multiple regression analysis for the natives, technology motivation, literacy/knowledge and skill contributed $43.3 \%$ of the variations in gratifications. For the migrants, in addition to literacy/knowledge, technology motivation and skill, together contributed to $43.3 \%$ of the variations in gratifications.

In contrast to the natives, the biggest $t$ value for the migrants is literacy knowledge. Thus, in terms of impact on gratifications derive from using the Internet, technology motivation and literacy knowledge have the biggest impact on gratifications for both the natives and migrants respectively. What this means is that the technology itself, in this case the Internet, has features that are attractive and motivating for the respondents of this study who are young and belong to the generation $y$. Studies have proven that the nature of the Internet is what makes it stand out from the conventional media (Laudon \& Laudon, 2000). For the migrants, who belong to the generation $x$, literacy knowledge is more important factor and has greater impact as long as deriving gratification from the Internet is concerned. This concurs with the findings by Rahim and Pawanteh (2011) that apart from investing in appropriate infrastructure, facilitating media literacy is also important.

Apart from the $t$ value which shows impact, the beta value helps us understand the predictors that have effects on gratifications. Similar to the $t$ value, it is motivation technology and literacy knowledge which have the largest beta value for both the natives and migrants. These two variables have bigger effects on gratification.

Information and socialisation gratification are the main gratifications derived from using the Internet for both the natives and migrants. With a huge storage of information and numerous social networking sites, the Internet, is indeed expected to provide gratifications for Internet users and both the natives and migrants users of Internet in this study are not left out in reaping these gratifications.

As far as the natives and migrants are concern having internet access / subscription does not contribute to gratification. Internet users can access the Internet at various places. Likewise, the number of hours one uses the Internet does not contribute to gratification. This means gratification can be derived base on the quality of usage and not quantity or number of hours one use the Internet.

\section{Suggestions for digital inclusion}

The young Internet users, the natives spend more hours socialising on the net with friends and family. For this group of people to continue using the Internet, efforts must be made to provide more facilities for social networking with added values for empowerment with the aim of achieving Digital inclusion.

The Internet is increasingly becoming a place to buy and sell things. Hence for an all inclusive digital inclusion, the use of Internet for shopping/e-business must be encouraged. As it is now, the use of this application is very minimal among the natives and migrants in this study.

Both the natives and migrants of this study get gratification from information and socialization use of the Internet. This, calls for a step up of the information and socialization gratification benefits derive from using the Internet. By this effort, a lasting digital inclusion will be attained.

To increase the gratifications derived from using the Internet, technology motivation and literacy knowledge of the Internet need to be further improved. From the findings, these variables have high impact on gratifications and improving them will improve the gratifications derive from the Internet resulting in digital inclusion for both 
the natives and migrants. The very nature of the Internet technology should be attractive and appealing to the young generation, while what is crucial for the older generation is the provision of ICT literacy and knowledge to speed up digital inclusion.

\section{Conclusion}

This study has met the objectives set by determining the variables that contribute to gratifications leading to digital inclusion. Overall, the literacy/knowledge of and skills of both the natives and migrants respondents about the Internet applications is above average and this is a contributing and determining factor towards digital inclusion, couple with the gratification derived from using the Internet.

The findings of this study have implied that there is no marked difference for the gratifications derived from using the Internet between the natives and migrants. Wherever differences exist, the gap is not wide as exhibited by the means of the variables.

In achieving digital inclusion, efforts must be made to provide more facilities for social networking. Also, for an all inclusive digital inclusion, the use of Internet for shopping/e-business must be encouraged. Furthermore, the information and socialization gratifications derive from using the Internet have to be stepped up. Last but not the least, the literacy/knowledge of the users and technology motivation of the Internet need to be further improved in order to achieve an inclusive digital inclusion in the long run.

\section{References}

Campbell, D. (2001). Can the digital divide be contained? International Labour Review, 140 (2): 43-55. http://dx.doi.org/10.1111/j.1564-913X.2001.tb00217.x

Cho, J., Zúñiga, H. G., Rojas, H. \& Shah, D. V. (2003). Beyond Access: The Digital Divide and Internet Uses and Gratifications. It \& Society, 1 (4): 46-72.

Cullen, R. (2001). Addressing the digital divide. Online Information Review, 5:311-320. http://dx.doi.org/10.1108/14684520110410517

Guilford J.P. \& Benjamin F. (1973). Fundamental Statistics in Psychology and Education. New York: McGraw Hill Book Co.

Hasim, M. S. \& Salman, A. (2010). Factors affecting sustainability of internet usage among youth. The Electronic Library, 28 (2): 300-313. http://dx.doi.org/10.1108/02640471011033657

Hebatallah El Gamal. (2010). Network society: A social evolution powered by youth. Global Media Journal, 1(1): 16-26.

Hirt, J., Murray, J. \& McBee, J. (2000). Technology and diversity: A pending collision on the information superhighway? NASPA Journal, 38(1): 47-58.

Hoffman, D., \& Novak, T. (1999). The growing digital divide: implications for an open research agenda. Retrieved $27^{\text {th }}$ August, from: http://ecommerce.vanderbilt.edu/

Howard, P.E., Rainie, L. \& Jones, S. (2001). Days and nights on the Internet: The impact of a diffusing technology. American Behavioral Scientist, 45(3): 383-404.

Katz, J. E., Rice, R. E., \& Aspden, P. (2001). The Internet, 1995-2000: Access, civic involvement, and social interaction. American Behavioral Scientist, 45(3): 405-419.

Kavanaugh, A. L., \& Patterson, S. J. (2001). The impact of community computer networks on social capital and community involvement. American Behavioral Scientist, 45(3): 496-509. http://dx.doi.org/10.1177/00027640121957312

Kent, D. \& McClure, D. P. (2009). Digital Inclusion: Bringing the rest of America online with broadband. US Internet Industry Association.

Kunigami, A. M. (2010). Digital Inclusion: Beyond Access to Broadband. AHCIET Magazine.

Laudon, K.C. \& Laudon, J. P. (2000). Management Information Systems: Organisation and Technology in the Networked Enterprise (6th ed.). New Jersey: Prentice Hall.

Mossberger, K., Tolbert, C. J. \& Stansbury, M. (2003). Virtual Inequality: Beyond the Digital Divide. Washington, D. C.: Georgetown University Press.

Norris, P. (2001). Digital divide: civic engagement, information poverty, and the Internet worldwide. New York: Cambridge University Press. 
OECD. (2001). Understanding the digital divide. Paris: OECD. Retrieved $25^{\text {th }}$ August, from: http://www.oecd.org/dataoecd/38/57/1888451.pdf

Rahim, S. A. \& Pawanteh, L. (2011). Democratization of Information in Malaysia: A Response to Globalization. Asian Social Science, 7(2): 3-11.

Schiller, D. (2000). Digital capitalism: Networking the global market system. London: MIT Press.

Smolenski, M. (2000). The Digital Divide and American Society: A Report on the Digital Divide and its Social and Economic Implications for Our Nation and Its Citizens. Retrieved $5^{\text {th }}$ August, from: http://www.gartner.com/public/static/techies/digital_d/dividehome.html

Stiakakis, E., Kariotellis, P. \& Vlachopoulou, M. (2010). From the Digital Divide to Digital Inequality: A Secondary Research in the European Union. In Sideridis, A. B. and Patrikakis, Ch. Z. (Eds.), e-Democracy 2009. LNICST, 26: 43-54.

TU. (2010). World Telecommunication/ICT Development Report 2010. Retrieved September 7, 2010, from: http://www.uis.unesco.org/Communication/Documents/WTDR2010_e.pdf

UN. (2005). The digital divide: ICT development indices 2004. United Nations Conference on Trade and Development. United Nations, New York and Geneva, 2005.

Wynne, M. E., \& Cooper, L. F. (2007). Power Up: The Campaign for Digital Inclusion - Digital Inclusion Imperatives Offer Municipalities New Social and Economic Opportunitites. Microsoft.

Table 1. Demographic Profile of Respondents

\begin{tabular}{|c|c|c|}
\hline & Natives & Migrants \\
\hline \multicolumn{3}{|l|}{ Gender } \\
\hline Male & $152(50.7 \%)$ & $151(50.3 \%)$ \\
\hline Female & $148(49.3 \%)$ & $149(49.7 \%)$ \\
\hline \multicolumn{3}{|l|}{ Age } \\
\hline $18-30$ & 300 & \\
\hline $31-48$ & - & 300 \\
\hline \multicolumn{3}{|l|}{ Marital status } \\
\hline Married & $51(17 \%)$ & $233(77.7 \%)$ \\
\hline Single & $249(83 \%)$ & $67(22.3 \%)$ \\
\hline \multicolumn{3}{|l|}{ Employment } \\
\hline Full time & $125(41.7 \%)$ & $229(76.3 \%)$ \\
\hline Part Time & $17(5.7 \%)$ & $19(6.3 \%)$ \\
\hline Unemployed & $17(5.7 \%)$ & $11(3.7 \%)$ \\
\hline Student & $140(46.7 \%)$ & $14(4.7 \%)$ \\
\hline Homemaker & $1(0.3 \%)$ & $27(9.0 \%)$ \\
\hline \multicolumn{3}{|l|}{ Academic Qualification } \\
\hline Postgraduate & $40(13.3 \%)$ & $48(16.0 \%)$ \\
\hline Bachelors & $81(27 \%)$ & $70(23 \%)$ \\
\hline Diploma/A' Level & $105(35 \%)$ & $65(21.7 \%)$ \\
\hline SPM /GCE O’Level & $55(18.3 \%)$ & $90(30 \%)$ \\
\hline Lain-lain & $19(6.3 \%)$ & $27(9 \%)$ \\
\hline \multicolumn{3}{|l|}{ Monthly Income } \\
\hline Not more than RM500 & $9(3 \%)$ & $12(4 \%)$ \\
\hline RM600-RM1400 & $62(20.7 \%)$ & $61(20.3 \%)$ \\
\hline RM1500-RM2500 & $80(26.7 \%)$ & $110(36.7 \%)$ \\
\hline More than RM3000 & $11(3.7 \%)$ & $71(23.7 \%)$ \\
\hline
\end{tabular}


Table 2. Internet Access

\begin{tabular}{|c|c|c|}
\hline & Natives & Migrants \\
\hline Internet Access/subscription & $215(71.7 \%)$ & $222(74 \%)$ \\
\hline \multicolumn{3}{|l|}{ Years of Internet Usage } \\
\hline Less than $6 \mathrm{mths}$ & $24(8 \%)$ & $29(9.7 \%)$ \\
\hline $6 \mathrm{mths}$ to $1 \mathrm{yr}$ & $34(11.3 \%)$ & $52(17.3 \%)$ \\
\hline 2 to $3 \mathrm{yrs}$ & $72(24 \%)$ & $92(30.7 \%)$ \\
\hline 4 to $5 \mathrm{yrs}$ & $56(18.7 \%)$ & $33(11 \%)$ \\
\hline More than 5 yrs & $114(38 \%)$ & $94(31.3 \%)$ \\
\hline \multicolumn{3}{|l|}{ Hours of Internet Usage } \\
\hline Never use & $32(10.7 \%)$ & $67(22.3 \%)$ \\
\hline Less than 3 hrs per week & $72(24 \%)$ & $83(27.7 \%)$ \\
\hline 4 to $7 \mathrm{hrs}$ per week & $51(\mathbf{1 7 \%})$ & $48(16 \%)$ \\
\hline 8 to $11 \mathrm{hrs}$ per week & $46(15.3 \%)$ & $30(\mathbf{1 0 \%})$ \\
\hline 12 to $14 \mathrm{hrs}$ per week & $99(\mathbf{3 3} \%)$ & $72(\mathbf{2 4} \%)$ \\
\hline
\end{tabular}

Table 3. Literacy/Knowledge of various Internet Applications (Mean and Standard Deviation [SD])

\begin{tabular}{lllll}
\hline & \multicolumn{2}{c}{ Natives } & \multicolumn{2}{c}{ Migrants } \\
& Mean & SD & Mean & SD \\
& & & & \\
\hline Email & 3.86 & .927 & 3.55 & 1.086 \\
Social Media (Facebook, & $\mathbf{3 . 9 2}$ & .909 & 3.57 & 1.043 \\
Twitter, Myspace, etc) & & & & \\
Blog & 3.19 & 1.115 & 2.94 & 1.199 \\
Search Engine & 3.90 & .934 & 3.64 & 1.061 \\
Online games & 3.14 & 1.111 & 2.81 & 1.185 \\
Downloading and & 3.61 & .973 & 3.24 & 1.122 \\
Uploading of Music, & & & & \\
Video, etc & & & & \\
Online banking & 2.99 & 1.210 & 2.91 & 1.241 \\
E-shopping/e-business & $\mathbf{2 . 6 6}$ & 1.201 & 2.72 & 1.236 \\
& & & & \\
\hline
\end{tabular}


Table 4. Gratification from using Internet (Mean and Standard Deviation [SD])

\begin{tabular}{|c|c|c|c|c|}
\hline & \multicolumn{2}{|c|}{ Natives } & \multicolumn{2}{|c|}{ Migrants } \\
\hline & Mean & SD & Mean & SD \\
\hline Quick on current issues & 4.22 & .828 & 4.12 & .836 \\
\hline Quick on information & 4.30 & .799 & 4.18 & .769 \\
\hline Easy making Friends & 4.09 & .923 & 4.02 & .795 \\
\hline $\begin{array}{l}\text { Realtime interaction } \\
\text { with friends }\end{array}$ & 3.97 & .826 & 3.95 & .840 \\
\hline $\begin{array}{l}\text { People get to know me } \\
\text { through blog }\end{array}$ & 3.60 & 1.054 & 3.49 & 1.068 \\
\hline $\begin{array}{l}\text { Internet shopping makes } \\
\text { it easy to choose }\end{array}$ & 3.21 & 1.153 & 3.22 & 1.177 \\
\hline $\begin{array}{l}\text { Easy to get materials / } \\
\text { books for reference }\end{array}$ & 3.52 & 1.096 & 3.44 & 1.094 \\
\hline $\begin{array}{l}\text { Social Media makes it } \\
\text { easier to give opinion }\end{array}$ & 3.83 & .928 & 3.65 & 1.050 \\
\hline $\begin{array}{l}\text { Confidence in mixing with } \\
\text { friends because I get lot of } \\
\text { information from internet }\end{array}$ & 3.80 & .922 & 3.66 & .960 \\
\hline $\begin{array}{l}\text { Internet provides me with } \\
\text { information to solve } \\
\text { problems }\end{array}$ & 4.06 & .896 & 3.83 & .951 \\
\hline $\begin{array}{l}\text { Internet help relieves } \\
\text { boredom }\end{array}$ & 4.10 & .879 & 3.81 & 1.014 \\
\hline $\begin{array}{l}\text { Happy playing } \\
\text { Online games }\end{array}$ & 3.40 & 1.213 & 3.08 & 1.243 \\
\hline $\begin{array}{l}\text { Can make online } \\
\text { transaction / pay bills }\end{array}$ & 3.51 & 1.158 & 3.48 & 1.152 \\
\hline
\end{tabular}

Table 5. Reliability Index of the Variables

\begin{tabular}{lccl}
\hline & Alpha $(\mathrm{n}=600)$ & No. of Items & Level of Reliability \\
\hline Internet Access/Usage & 0.80 & 9 & Very satisfactory \\
Technological Motivation & 0.67 & 18 & Average \\
Literacy/knowledge & 0.90 & 8 & Very satisfactory \\
Skill & 0.91 & 22 & Very satisfactory \\
Participation & 0.93 & 22 & Very satisfactory \\
Gratification & 0.90 & 13 & Very satisfactory \\
& & & \\
\hline
\end{tabular}


Table 6. Regression Analysis (Stepwise) for Variables contributing to variations in Gratification

$$
\text { Natives }(\mathrm{n}=300)
$$

\begin{tabular}{llcccccc}
\hline Model & R & RSqr & Adj RSqr & B & t & \multicolumn{1}{l}{ Sig } & F \\
\hline A & & & & & & & \\
Constant & & & & 6.171 & 1.663 & .000 & 138.756 \\
MotvTECH & .564 & .318 & .315 & .673 & 11.779 & .000 & \\
& & & & & & & \\
\hline B & & & & & & \\
Constant & & & & 5.138 & 1.503 & .000 & 109.178 \\
MotvTECH & .651 & .424 & .420 & .481 & 8.198 & .000 & \\
LiteracyKnowledge & & & & .493 & 7.391 & .000 & \\
& & & & & & & \\
\hline C & & & & & & & \\
Constant & & & & 3.808 & 1.116 & .000 & 77.052 \\
MotvTECH & .662 & .438 & .433 & .463 & $\mathbf{7 . 9 2 8}$ & .000 & \\
LiteracyKnowledge & & & & .351 & 4.213 & .000 & \\
Skill & & & & .124 & 2.793 & .006 & \\
& & & & & & &
\end{tabular}

Migrants $(\mathrm{n}=300)$

\begin{tabular}{|c|c|c|c|c|c|c|c|}
\hline Model & $\mathbf{R}$ & $\mathbf{R S q r}$ & Adj RSqr & B & $\mathbf{t}$ & Sig & $\mathbf{F}$ \\
\hline \multicolumn{8}{|l|}{$\mathrm{A}$} \\
\hline Constant & & & & 29.973 & 19.843 & .000 & 153.266 \\
\hline LiteracyKnowledge & .583 & .340 & .337 & .708 & 12.380 & .000 & \\
\hline \multicolumn{8}{|l|}{ B } \\
\hline Constant & & & & 10.449 & 3.068 & .000 & 106.495 \\
\hline LiteracyKnowledge & .646 & .418 & .414 & .505 & 8.054 & .000 & \\
\hline MotvTECH & & & & .387 & 6.307 & .000 & \\
\hline \multicolumn{8}{|l|}{$\mathrm{C}$} \\
\hline Constant & & & & 9.688 & 2.880 & .000 & 77.163 \\
\hline LiteracyKnowledge & .662 & .439 & .433 & .367 & 6.054 & .000 & \\
\hline MotvTECH & & & & .303 & 3.51 & .000 & \\
\hline Skill & & & & .150 & 3.345 & .001 & \\
\hline
\end{tabular}

Dependent Variable: Gratification 
Table 7. Beta values for the predictor variables

\section{Natives}

\begin{tabular}{lcc}
\hline Predictor Variables & $\begin{array}{c}\text { Beta } \\
\text { (Standardised coefficient) }\end{array}$ & $\begin{array}{c}P \\
\text { (Significant) }\end{array}$ \\
\hline Motivated by Technology &. $\mathbf{3 8 8}$ & .000 \\
Literacy / Knowledge & .258 & .000 \\
Skills & .166 & .006 \\
& & \\
\hline
\end{tabular}

Migrants

\begin{tabular}{lcc}
\hline Predictor Variables & Beta & $P$ \\
& (Standardised coefficient) & (Significant)
\end{tabular}

\begin{tabular}{lll}
\hline Literacy / Knowledge & $\mathbf{. 3 0 4}$ & .000 \\
Motivated by Technology & .253 & .000 \\
Skills & .222 & .001
\end{tabular}

